Lexical and Syntactic Causatives in Oromo

Author(s): Stanley Dubinsky, Maria-Rosa Lloret and Paul Newman

Source: Language, Vol. 64, No. 3 (Sep., 1988), pp. 485-500

Published by: Linguistic Society of America

Stable URL: http://www.jstor.org/stable/414530

Accessed: 26-04-2016 14:27 UTC

Your use of the JSTOR archive indicates your acceptance of the Terms \& Conditions of Use, available at

http://about.jstor.org/terms

JSTOR is a not-for-profit service that helps scholars, researchers, and students discover, use, and build upon a wide range of content in a trusted

digital archive. We use information technology and tools to increase productivity and facilitate new forms of scholarship. For more information about JSTOR, please contact support@jstor.org.

Linguistic Society of America is collaborating with JSTOR to digitize, preserve and extend access to Language 


\title{
LEXICAL AND SYNTACTIC CAUSATIVES IN OROMO
}

\author{
Stanley Dubinsky \\ Maria-Rosa Lloret \\ University of California, \\ Santa Cruz \\ Indiana University \\ PAUl NewMAN \\ Indiana University
}

In the syntactic process of causative formation in Oromo, the affixation of the causative morpheme is sensitive to initial grammatical relations: the number of causative morphemes corresponds to the number of logical subjects in the clause. Thus, transitive and unergative verbs can be distinguished from unaccusatives in causative constructions. A causative-intensive construction may also be formed via reduplication of this causative morpheme. However, not all predicates that appear to be causatives can be intensified in this way. We propose that these predicates (a restricted number of unaccusative verb stems) combine derivationally with the causative morpheme, and that the output of this derivation may not be intensified. Oromo, then, shows the distinct effects of similar morphological processes arising either in the lexicon or in the syntax.*

1. In Oromo (formerly known as Galla), a Cushitic language of Ethiopia and Kenya, the formation of causatives is accomplished through the affixation of a bound morpheme $-s$ (with surface variants $/ \check{c} /, /$ is/, and /iis/) and the addition of an appropriate argument: ${ }^{1}$

(1) a. aannan-ni daanf-e.

milk-NOM boil-AGR ${ }^{2}$

'The milk boiled.'

b. terfaa- $n$ aannan daanf-is-e.

NOM milk boil-CAU-AGR

'Terfa made the milk boil' (i.e., 'Terfa boiled the milk').

The affixation of an additional $-s$ and an argument to an already causativized form results in a multiple causative.

(2) terfaa-n gamteessaa aannan daanf-is-iis-e.

NOM milk boil-CAU-CAU-AGR

'Terfa made Gamtesa boil the milk.'

As was shown in Lloret 1987, verbs can be classified according to whether their initial causative forms require one $-s$ morpheme or two (the vowel /i(i)/ between the two $-s$ 's in $-s i(i) s$ is added by a rule of epenthesis).

* An earlier version of this paper was presented at the 18th Conference on African Linguistics in Montreal in April, 1987. We would like to thank Addisu Tolesa for his invaluable help and coöperation in the compilation and interpretation of the Oromo examples which were elicited between 1985 and 1988 at Indiana University. We would further like to express our gratitude to the following individuals for their valuable comments and suggestions: Robert Botne, William Bright, Greville Corbett, William Davies, Geoffrey Pullum, and Laurie Tuller. We also acknowledge the constructive criticisms provided by the anonymous reviewers for Language. All errors and omissions are the responsibility of the authors.

${ }^{1}$ The major general sources on Oromo on which we have relied are Gragg 1976 and 1982, Moreno 1939, and Owens 1985a. Oromo causatives in particular have been treated in Hayward 1976, Lloret 1987, and Owens 1985b. The classic comparative overview of causatives in the Cushitic family is Plazikowsky-Brauner 1959.

${ }^{2}$ AGR is a person/number/tense agreement marker; NOM is an overt nominative case marker. 
(3) gog- 'be dry' Dug- 'drink' ${ }^{3}$ gogs- 'make dry' Dugsiis- 'make drink'

Hayward (1976:33) noted that this division correlates with the number of agentive nominals in the resultant causative construction. Thus, causatives formed from transitive verbs or from what Hayward terms 'agentive' intransitives are affixed with two $-s$ morphemes, while those formed from 'non-agentive' intransitives are affixed with one $-s$ morpheme.

(4) a. Dugsiis- 'makedrink' (<Dug-'drink') (transitive)

terfäa-n gamteessaa aannan Dug-siis-e.

NOM milk drink-CAU-AGR

'Terfa made Gamtesa drink milk.' (2 agentives)

b. fiigsis- 'make run' ( $<$ fiig- 'run') (agentive intransitive)

terfāa $-n$ gurbaa fiig-sis-e.

NOM boy run-CAU-AGR

'Terfa made the boy run.' ( 2 agentives)

c. daanfis- 'make boil' (< daanf- 'boil') (non-agentive intransitive)

terfaa-n aannan daanf-is-e.

NOM milk boil-CAU-AGR

'Terfa boiled the milk.' (1 agentive)

Hayward's proposal that the number of $-s$ 's matches the number of agentive nominals in a sentence also explains the formation of multiple causatives wherein an $-s$ morpheme is affixed to a causativized form and an additional agentive argument is added.

(5) a. gamteessaa- $n$ terfaa aannan daanf-is-iis-e.

$$
\text { NOM milk boil-CAU-CAU-AGR }
$$

'Gamtesa made Terfa boil the milk.' (2 agentives, $2 s$ 's)

b. gamteessaa-n terfaa gurbaa fiig-sis-iis-e.

NOM boy rUn-CAU-CAU-AGR

'Gamtesa made Terfa make the boy run.' (3 agentives, 3 s's)

1.1. While Hayward's account is appealing at first sight, it soon runs into problems. First, it is not the case that the subjects of all so-called 'agentive' intransitives - 'cry', 'swim', 'be angry', etc. - can be characterized as actually manifesting the semantic/thematic role 'agent'. For example, from a semantic/ thematic perspective, the subject of the 'agentive' intransitive Deekam- 'be angry', which forms its causative with two $-s$ morphemes, does not appear to be any more of an agent than the subject of the 'non-agentive' intransitive fayy'be healthy', which takes only one $-s$.

(6) Deekam- 'be angry' $\rightarrow$ Deekamsiis- 'make angry' fayy- 'be healthy' $\rightarrow$ fayyis- $\quad$ 'make healthy'

Furthermore, the subjects of transitive verbs of perception ('hear', 'see', etc.), which in most accounts are understood to have the thematic role 'experiencer' rather than 'agent', also form their causative with two $-s$ morphemes.

(7) arg- 'see' $\rightarrow$ argisiis- 'make see'

\footnotetext{
${ }^{3}$ In the transcription, the symbol /D/ represents an implosive retroflex stop. The use of an apostrophe indicates that the consonant is an ejective, e.g. / $̌$ \%
} 
1.2. Second, one finds that the addition of an $-s$ morpheme to a causativized form does not always correspond to the addition of another agentive nominal. The additional $-s$ in $8 \mathrm{~b}$, for example, serves to intensify the nature of the causation rather than to add a further causative.

(8) a. terfaa-n gurbaa raff-is-e. NOM boy sleep-CAU-AGR

'Terfa put the boy to sleep (e.g. by rocking him).'

b. terfaa-n gurbaa raff-is-iis-e. NOM boy sleep-CAU-INT-AGR

'Terfa made the boy sleep (e.g. by giving him a sleeping pill).'

2.1. The first problem can be handled by looking at the number of $-s$ morphemes in causative constructions in terms of grammatical relations rather than of thematic roles. That is, we are still operating in the spirit of Hayward's approach, but we are suggesting that the correlation is really between $-s$ morphemes and grammatical subjects rather than between $-s$ morphemes and thematic agents. Our proposal is that the verbs which form their causatives via a single $-s$ morpheme are all unaccusatives, i.e. verbs whose single argument is initially a direct object; by contrast, verbs which form causatives with two $-s$ morphemes are either transitive (verbs that select an initial subject and direct object) or unergative (verbs that select an initial subject only). Using the relational notation of $\mathbf{1}$ for subject, $\mathbf{2}$ for direct object, and $\mathrm{P}$ for predicate, the relational networks of clauses containing each of these three classes of verbs are represented in 9.

(9) a. terfaa-n aannan Dug-e. NOM milk drink-AGR 'Terfa drank the milk.'

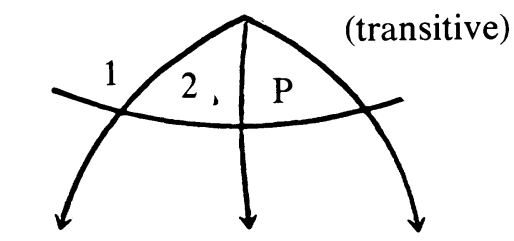

terfaa

aannan

Dug-

b. terfaa-n fiig-e. NOM run-AGR 'Terfa ran.'

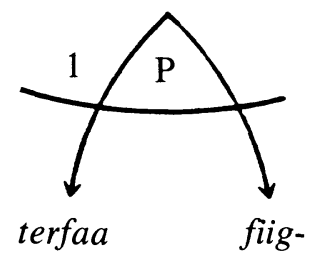

c. aannan-ni daanf-e. milk-NOM boil-AGR

'The milk boiled.'

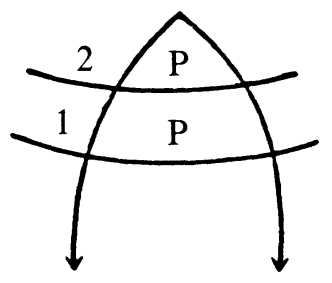

(unaccusative)

(unergative)

aannan daanf- 
In 9c, the initial direct object of daanf- 'boil' advances to subject to satisfy the universal requirement that every basic clause have a final subject (the Final 1 Law; Perlmutter 1980, Johnson \& Postal 1980); ${ }^{4}$ underlyingly, daanf- 'boil' and other verbs of this class are subjectless. While the intransitive sentences $9 \mathrm{~b}$ and $9 \mathrm{c}$ are structurally parallel on the surface, underlyingly they are presumed to be grammatically distinct. Note that in our analysis a verb such as Deekam- 'be angry', which takes two $-s$ morphemes in the causative, differs from a verb such as fayy- 'be healthy', which takes only one $-s$, not in any intrinsic semantic agentivity of its surface subject but in its language-specific categorization as an unergative as opposed to an unaccusative verb. ${ }^{5}$

(10) a. terfaa-n Deekam-e.

NOM be.angry-AGR

'Terfa was angry.'

(cf. a'. gamteessaa terfaa Deekamsiise.)

'Gamtesa made Terfa angry.'

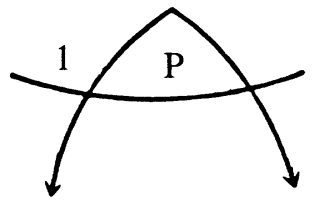

terfaa

Deekam-

b. terfaa-n fayy-e.

NOM be.healthy-AGR

'Terfa was healthy.'

(cf. $\mathrm{b}^{\prime}$. gamteessaa terfaa fayyise.)

'Gamtesa made Terfa healthy.'

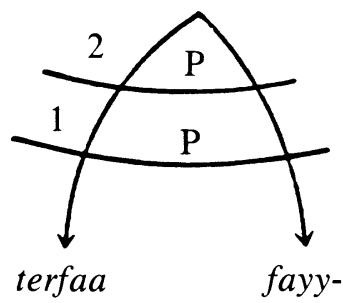

The causative construction under examination here is taken to be a union construction in the sense of Davies \& Rosen 1988. In the formation of a causative, the morpheme $-s$, which is itself a predicate, is introduced into the clause along with an additional subject argument. The subject of the embedded predicate (when present) is uniformly revalued as a direct object. The embedded

${ }^{4}$ A conceptually similar principle proposed by Chomsky (1982:10) is the extended part of the Extended Projection Principle. The Projection Principle is as follows: 'Representations at each syntactic level are projected from the lexicon in that they observe the subcategorization properties of lexical items' (Chomsky 1981:29). The Projection Principle, along with the requirement that clauses have subjects, is the Extended Projection Principle.

${ }^{5}$ The authors acknowledge that there is not, so far as we can determine, any other syntactic evidence that independently motivates the unergative/unaccusative distinction proposed here. In this respect, our proposal is, prima facie, circular. Nevertheless, we feel that our proposal is justified on other grounds. The categorization we have made on the basis of morphological correlations in causative constructions divides the intransitive verbs of Oromo into groups that are semantically prototypical of the unergative/unaccusative classes encountered in many other languages for which the purely syntactic motivation is more salient. Verbs that determine an unaccusative initial stratum are more often than not 'predicates expressed by adjectives in English...predicates whose [single argument] is semantically a patient...predicates of existing and happening...aspectual...[and] durative [predicates]...' (Perlmutter \& Postal 1984:94-100). Unaccusative predicates are also, in the main, non-volitional (however, cf. Rosen 1984:61-73 for qualifications). Examining the list of Oromo verbs proposed to be unaccusatives, we find that they fit quite well into the expected semantic classes: 'boil (INTR)', 'be healthy', 'break (INTR)', 'be lazy', 'be dry', etc. 
predicate and the embedded direct object of a transitive predicate lose their relational status and become Chômeurs (CHO); this is consistent with the Stratal Uniqueness Law, which provides that no two dependents can bear the same grammatical relation in the same stratum (Johnson \& Postal 1980; see also Dubinsky 1985 and 1988 for the appropriate revision of this law).

(11) a. =(4a)

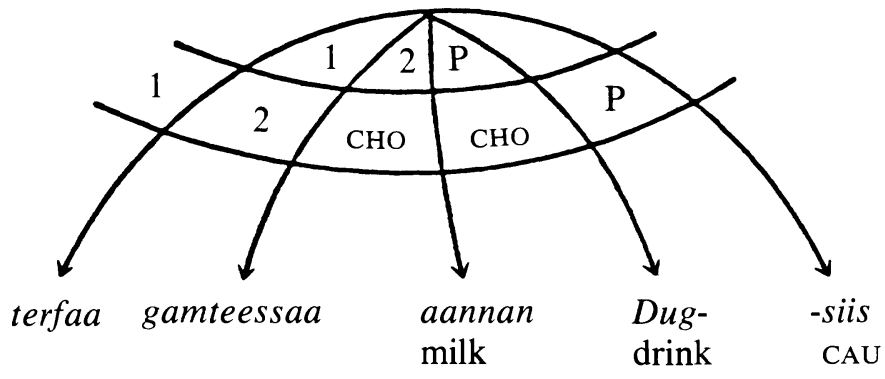

b. $=(4 b)$

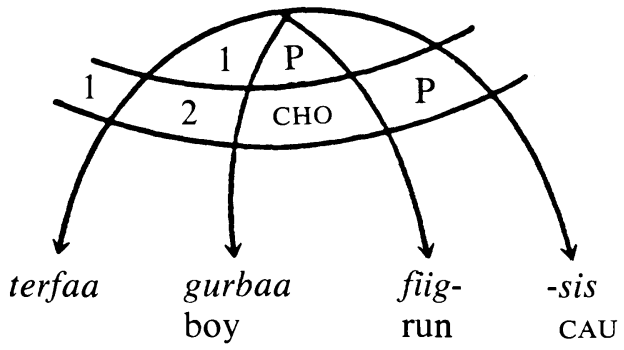

c. $=(4 \mathrm{c})$

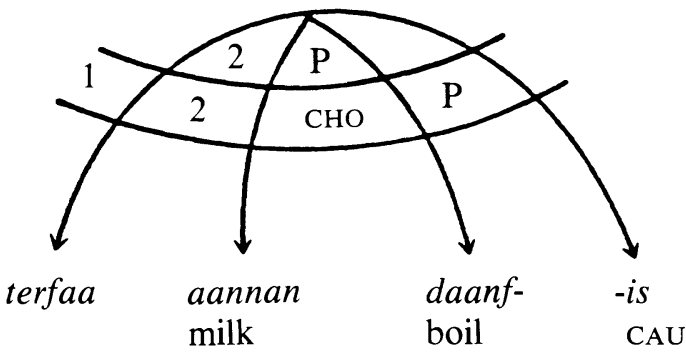

We can attribute the realization of each $-s$ morpheme in a causative to the presence of a subject in the clause. Thus, since the verbs Dug- 'drink' and fiig'run' each introduce their own subject nominals (in addition to that added by the causative morpheme itself), their causatives show up with two $-s$ affixes. In the case of the construction formed with the unaccusative predicate daanf'boil', only the causative predicate $-s$ introduces a subject, and therefore, only one $-s$ affix shows up.

2.2. This analysis does not address the second problem for Hayward's treatment of causatives, namely, the existence of causative constructions which add an $-s$ but do not add an agentive argument. The explanation here lies in an understanding of the CAUSATIVE-INTENSIVE construction, which, with the ex- 
ception of Lloret 1987, has been neglected in the Oromo literature. Attention to the causative-intensive construction, moreover, provides important evidence that allows one to distinguish more accurately the nature of causative phenomena in Oromo. While $-s$ is usually described (and usually functions) as a causative morpheme tied to the number of underlying grammatical subjects, it can, as was shown above in 8, serve as an intensifier (INT).

(12) a. terfaa-n toltuu gurbaa aannan Dug-siis-is-e. NOM boy milk drink-CAU-CAU-AGR

'Terfa made Toltu make the boy drink the milk.'

b. toltuu-n gurbaa aannan Dug-siis-is-e. NOM boy milk drink-CAU-INT-AGR 'Toltu made (forced) the boy to drink the milk.'

There are, however, strict limitations on the use of $-s$ in its intensive function. While the causatives of all transitive verbs and all unergative intransitives allow the addition of the INT, only sOME unaccusative verbs (verbs that form their causative with a single $-s$ ) do so. For example, the addition of $-s$ to the causative gogs- 'make dry' can result in a double causative or an intensive, depending on the number of overt arguments.

(13) a. terfaa-n gamteessaa muka gog-s-iis-e. NOM wood dry-CAU-CAU-AGR

'Terfa made Gamtesa make the wood dry.'

b. terfaa-n muka gog-s-iis-e.

NOM wood dry-CAU-INT-AGR

'Terfa made[+INT] the wood dry.'

The form c'abs- 'make break', on the other hand, cannot form an intensive construction with the addition of $-s$. The affixation of $-s$ to $c^{\prime}$ 'abs- must necessarily be accompanied by the addition of an argument. Thus 14a is grammatical, while $14 \mathrm{~b}$ is ill-formed.

(14) a. terfaa-n toltuu tuwwee č'ab-s-iis-e.

NOM pot break-CAU-CAU-AGR

'Terfa made Toltu make the pot break.'

b. *terfaa-n tuwwee č'ab-s-iis-e.

NOM pot break-CAU-INT-AGR

'Terfa made[ + INT] the pot break.'

The double causative form č'absiis- 'make someone make something break', on the other hand, permits the addition of the INT $-s$. Thus, the affixation of $-s$ in 15 may, but need not, add an argument.

(15) a. terfaa-n toltuu gamteessaa tuwwee čab-s-iis-is-e. NOM pot break-CAU-CAU-CAU-AGR

'Terfa made Toltu make Gamtesa make the pot break.'

b. terfaa-n toltuu tuwwee č'ab-s-iis-is-e.

NOM pot break-CAU-CAU-INT-AGR

'Terfa made[ + INT] Toltu make the pot break.'

It is important to note that the intensifier $-s$ is only an intensifier of causatives. It cannot be affixed to a bare uncausativized verb. The fact that INT $-s$ cannot 
be attached directly to simple stems, as is possible with polysemous causative/ intensive formations in Semitic (cf. Moscati et al. 1964:124), argues against the treatment of INT $-s$ and CAU $-s$ as distinct homophonous morphemes (cf. Hamp's 1985:64 claim to this effect for Sanskrit). An analysis more in keeping with the nature of Oromo and other Cushitic languages is that the causative $-s$ and the intensive $-s$ are essentially the same morpheme, but that they are introduced by distinct processes and have different grammatical consequences. The CAU $-s$ is added directly to any stem, where the number of $-s$ 's correlates with the number of subjects. The addition of an $-s$ to a causative verb requires the concomitant addition of a subject argument and produces a multiple causative. The causative-intensive construction, on the other hand, strengthens the nature of the causation by reduplicating the $-s$ found on a causative verb. ${ }^{6}$ Since the process of reduplication-intensification does not involve adding a new, independent CAU morpheme, it does not entail the addition of a new subject argument. This explains the seemingly puzzling non-fit in intensive-causative constructions between the number of $-s$ 's and the number of grammatical subjects represented.

(16) a. muk-ni gog-e.

wood-NOM dry-AGR

'The wood dried.'

b. *muk-ni gog-s-e.

wood-NOM dry-INT-AGR

'The wood dried[ + INT].'

(17) a. terfaa-n gurbaa Daan-e. NOM boy beat-AGR

'Terfa beat the boy.'

b. *terfaa-n gurbaa Daan-s-e. NOM boy beat-INT-AGR

'Terfa beat [ + INT] the boy.'

Our characterization of the causative-intensive as a reduplicative process finds further support in cross-linguistic comparisons. Like Oromo, a number of Southern Bantu languages-among them Nguni, Sotho, Venda, Tsonga, and Shona-form their causative by inflecting a verb stem with the morpheme -is or -es (Doke 1954). ${ }^{7}$ Some examples from Sotho are provided in 18 (Doke 1954:140-41).

(18) utloa 'hear' $\rightarrow$ utloisa 'cause to hear'

lula 'sit' $\rightarrow$ lulisa 'set down'

boolaea 'kill' $\rightarrow$ boolaisa 'cause to kill'

In some of these languages, the intensifier is often a reduplication of the cau-

\footnotetext{
${ }^{6}$ Adding an $-s$ and reduplicating an $-s$ produce verb stems with the same surface form, as in examples 13 and 15; but this doesn't affect the fundamental difference in the processes involved. While $2+2$ and $2 \times 2$ result in the same answer, they nevertheless manifest distinct operations.

${ }^{7}$ The observations on the parallels between Oromo and the Southern Bantu languages discussed here are due to Robert Botne. The similarity in the form of the causative morphemes in Cushitic and in Bantu is presumably fortuitous.
} 
sative morpheme. This is the case in Nguni (Doke 1954:105-106), Sotho (p. 141), and Tsonga (pp. 194-95).

$\begin{array}{lll} & \text { Causative } & \text { Intensive } \\ \text { Nguni: } & -i s a & -i s i s a \\ \text { Sotho: } & -i s a & -i s i s a \\ \text { Tsonga: } & -i s a & -i s i s a\end{array}$

The fact that this is reduplication and not a case of coincidental homophony between the causative marker and the intensive marker becomes further apparent when one examines other Southern Bantu languages. In Oshiwambo, for example, which has the causative morpheme $-i k$, we find the intensifier -ikik (Viljoen 1978). In Swazi there are three coexistent forms of the intensifier, all of them reduplications: -isis, -elel and -ulol (Ziervogel 1952). Nor is the phenomenon of reduplication encoding intensity peculiar to African languages. Moravcsik (1978:321-22), in a general discussion of reduplicative constructions, cites reduplicative intensifiers in Turkish, Sundanese, Agta, Telugu, Thai, and Tagalog.

3. Given that the INT is necessarily restricted to causative verbs, since it is formed by reduplicating an existent $-s$ causative morpheme, one might question whether those apparent causatives to which the intensifier cannot be attached (e.g. 14b) are truly causatives. Suppose that thie causative predicate $-s$, in addition to freely attaching to nearly any clause, also combines derivationally in the sense of Lieber 1981 with a limited class of verbs. ${ }^{8}$ This predicate, like any other, has a lexically specified valence. It minimally requires that its clause contain at least a subject and a direct object. We might represent this valence as in 20 .

$$
\text { (20) }-s:\left[\begin{array}{ll}
1 & 2
\end{array}\right]
$$

Thus, if causative $-s$ combines in the lexicon with a verb such as $\check{c}$ ' $a b$ - 'break', the resulting derived verb $\check{c}^{\prime} a b s$ - will have the structure in 21 .

(21) $\left[\mathrm{v}\left[\mathrm{v} \check{c} \check{c}^{\prime} a b\right] s\right]$

Since it is the head of the derived word, any lexical features on the affix $-s$ will be features of the derived form. Since the only relevant lexical feature carried by $-s$ is its valence, it functions derivationally as a transitivizing affix, deriving a transitive verb $\check{c}$ 'abs- 'break' from the intransitive verb $\check{c}^{\prime} a b$ 'break'. 9

\footnotetext{
${ }^{8}$ This lexical alternation between unaccusative and transitive predicates corresponds to what Marantz (1984:179-93) calls 'anticausativization'. In support of his claims, we have noted that this alternation is NOT lexically productive and is restricted to a 'semantically coherent class of verbs'.

${ }^{9}$ Interestingly, Jamison 1976 has argued that the Sanskrit 'causative' formative was originally a transitivizer and that it only later developed into a causative that could be used with transitive stems. In Hausa, the 'causative' morpheme (termed 'efferential' in Newman 1983) serves either to transitivize unergative intransitive verbs or else to indicate action directed away from the speaker (in a real or figurative sense). It does not form syntactic causatives with higher-level subjects.
} 
(22)

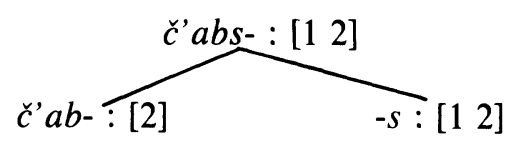

In 22, the unaccusative verb $\check{c}$ ' $a b$ - 'break' is seen to be categorized for an initial 2 (direct object) only. When we derivationally attach the CAU morpheme $-s$, its subcategorization requirements (an initial 1 and 2) are imposed on the derived form č'abs- in accordance with Lieber's Feature Percolation Convention (FPC) II. The meaning of the derived form is otherwise determined by the embedded stem $c^{\prime} a b$ - in accordance with FPC III. ${ }^{10}$

Thus, the formation of gogs- 'make dry' involves the sYNTACTIC affixation of causative $-s$ to a clause, but the formation of $c$ 'abs- 'break (trans)' involves the LEXICAL affixation of causative $-s$ to a verb stem. Accordingly, 23a is a causative union construction as expressed by its relational network, while 23b is a simple transitive clause containing a single predicate. ${ }^{11}$

(23) a. terfaa-n muka gog-s-e.

NOM wood dry-CAU-AGR

'Terfa made the wood dry.'

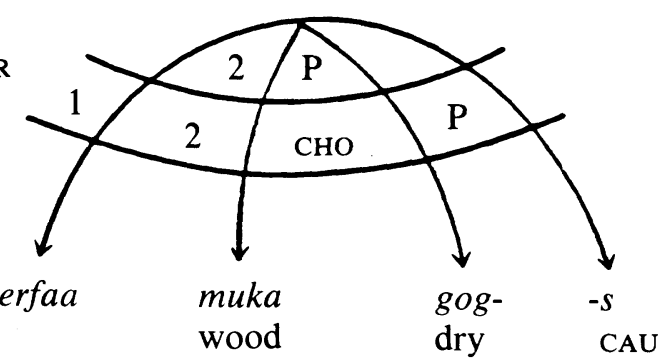

b. terfaa-n tuwwee č'abs-e. NOM pot break-AGR 'Terfa broke the pot.'

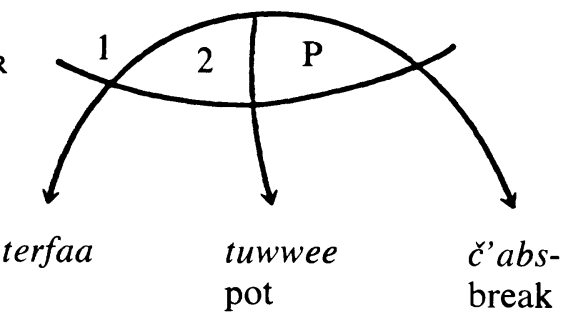

This analysis claims that gogs- can take an intensifier because it is a syntactic causative, while č 'abs- cannot take an intensifier because it is an uncausativized verb stem. However, as shown earlier in 15, čabsiis-, a syntactic causative built on the transitivized stem, can take an intensifier. In what follows, we will provide two additional motivations for the proposed lexical/syntactic distinction.

${ }^{10}$ The Feature Percolation Conventions referred to here are as follows (Lieber 1981:49-50):

Convention II: All features on an affix morpheme including category features percolate to the first branching node dominating that morpheme.

Convention III: If a branching node fails to obtain features by Convention II, features from the next lowest labeled node are automatically percolated up to the unlabeled branching node.

${ }^{11}$ The situation in Amharic described by Gragg 1970 is very similar to the one described here for Oromo. The big difference is that in Amharic the 'lexical' and the 'syntactic' causatives use different markers, a prefix $a$-for the former and a prefix $a s$ - for the latter. 
3.1. The first argument comes from the behavior of analytic causatives. In addition to the synthetic causative construction discussed above, Oromo has an analytic causative formed by the verb $g o D$ - 'make' and an embedded clause introduced by the complementizer $a k k a$. This construction contains an independent embedded clause, and the arguments of the complement clause maintain their normal case marking. The subject of $g o D$ - and the subject of the embedded verb are both marked nominatively. In 24 , the synthetic and analytic causatives are contrasted.

(24) a. terfaa-n gamteessaa leenč́' a ă̌ǰes- $(s) i s-e$. NOM lion kill-CAU-AGR

'Terfa made Gamtesa kill the lion.'

b. terfaa-n [akka gamteessaa-n leenč'a aǰjees-u] goD-e. NOM COMP NOM lion kill-AGR make-AGR

'Terfa made Gamtesa kill the lion.'

This analytic causative can also take a synthetically causativized complement clause, as in 25 . The result is a double causative.

(25) terfaa-n [akka gamteessaa-n gurbaa leenč $a$ aǰjees- $(s) i s-u$ ] NOM COMP NOM boy lion kill-CAU-AGR goD-e.

make-AGR

'Terfa made Gamtesa make the boy kill the lion.'

The verb goD- 'make' can itself be inflected to indicate intensive, i.e. goččisiis- 'make [+INT]'. ${ }^{12}$ This inflected form of goD- can, expectedly, take a complement clause to form an analytic intensive-causative. However, in the same way that the intensive morpheme $-s$ was seen to affix only to causativized verb forms, the intensive form of the verb 'make' goččisiis- only allows a causativized complement clause. The result is necessarily an intensive double causative. In 26a, we see that goččisiis- cannot take an uncausativized complement.

(26) a. *terfaa-n [akka gamteessaa-n leenč’a ă̌̌jees-u] NOM COMP NOM lion kill-AGR goččisiis-e. make[ + INT]-AGR

'Terfa made[+ INT] Gamtesa kill the lion.'

b. terfaa-n [akka gamteessaa-n gurbaa leenč'a NOM СOMP NOM boy lion a ǰjees-(s)is-u] goččisiis-e. kill-CAU-AGR make[ + INT]-AGR

'Terfa made[ + INT] Gamtesa make the boy kill the lion.'

\footnotetext{
12 The double / $/ \check{c} /$ in gočcisiis- comes from /Ds/ by means of the somewhat complicated, but regular, morphophonemic rules of Oromo (see Gragg 1976:176). The formation of 'make [+ INT]' follows the rules mentioned earlier in that the INT $-s$ morpheme is a reduplication of a CAU $-\mathrm{s}$ morpheme. The verb goD- 'make' is exceptional, however, in that the addition of the CAU $-s$ does not alter its meaning or argument structure. It would appear that, since the verb stem and the affix are semantically identical, the CAU $-s$ inflection only serves the purpose of feeding the INT reduplication rule.
} 
Our analysis predicts that the apparent causatives that we have characterized as being lexically derived should behave with respect to the selectional requirements of goččisiis- 'make[+INT]' as non-causativized verbs. This prediction is borne out in a comparison of the verb daanf- 'boil', which forms a causative with $-s$ (i.e. adds $-s$ syntactically), and the verb č' $a b$ - 'break', which combines with $-s$ derivationally (i.e. adds $-s$ lexically).

(27) a. *terfaa-n [akka aannan-ni daanf-u] goččisiis-e.

NOM COMP milk-NOM boil-AGR make[+ INT]-AGR

'Terfa made[ + INT] the milk boil.'

b. terfaa-n [akka gamteessaa-n aannan daanf-is-u] NOM COMP NOM milk boil-CAU-AGR goččisiis-e. make[ + INT]-AGR

'Terfa made[ + INT] Gamtesa make the milk boil.'

(28) a. *terfaa-n [akka tuwwee-n č'ab-u] goččisiis-e.

NOM COMP pot-NOM break-AGR make[ + INT]-AGR

'Terfa made[ + INT] the pot break.'

b. *terfaa-n [akka gamteessaa-n tuwwee č'abs-u] NOM COMP NOM pot break-AGR goččisiis-e. make[ + INT]-AGR

'Terfa made[ + INT] Gamtesa break the pot.'

Significantly, in 28b č'abs- 'break (TRANS)' cannot appear as the complement of goččisiis-; that is, it behaves as a non-causativized verb. If, however, č'absitself is causativized (i.e. adds an $-s$ syntactically), then the clause containing it CAN be a complement of goččisiis-, albeit a rather complex one.

(29) terfaa-n [akka gamteessaa-n gurbaa tuwwee č'abs-(s)iis-u] NOM COMP NOM boy pot break-CAU-AGR goččisiis-e. make[ + INT]-AGR

'Terfa made[ + INT] Gamtesa make the boy break the pot.'

3.2. The second outside motivation for the dichotomous lexical/syntactic analysis comes from the morphology of the causative itself. The processes of causative formation outlined above and described in detail in Lloret 1987 lead to further significant evidence in support of this analysis. We have already noted that: (1) simple transitive verbs are causativized by the addition of two $-s$ morphemes, while (2) if causativized verb forms are further causativized, they receive a single additional $-s$. Given our analysis of lexically produced 'causatives' as grammatically simple transitive verbs, the prediction stated in 30 follows naturally:

(30) The syntactically causativized forms under discussion should undergo further causativization by the affixation of a single $-s$ morpheme, while the LEXICALLY transitivized forms should require the affixation of two $-s$ morphemes $(-s i(i) s)$.

This prediction, although quite straightforward, turns out to be difficult to 
verify. There is a morphophonemic rule in Oromo that reduces one of the /s/'s when an affix beginning in /s/ is added to a stem that ends in /s/.

(31) $s$-reduction rule (Lloret 1987):

$$
[\ldots s]_{\text {stem }}+[s \ldots]_{\text {affix }} \rightarrow[\ldots . . .]
$$

Accordingly, adding -si(i)s to a transitive verb stem such as č'uqaas- 'shake' results in the form č'uqaasis- 'make shake'. Now, if one examines the causativized form of the proposed transitivized verb č' $a b s$ - 'break (TRANS)', it is impossible to determine whether the resultant form č ' absiis-contains the suffix -siis, which has been phonologically reduced (as would be expected of a transitive stem), or whether it contains -iis (as would be the case with syntactically causativized forms):

(32) $c$ a

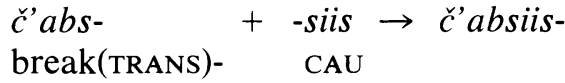

$$
\begin{aligned}
& \text { č'ab-s- + -iis } \rightarrow \text { čabsiis- } \\
& \text { break-CAU- CAU }
\end{aligned}
$$

Fortunately, there do exist forms which allow the claim to be tested. If $-s$ is added to a verb stem ending in $/ 1 /$, it becomes $/ \check{c} /$ in accordance with a general palato-affricate rule (Lloret 1987). The affixation of $-s$ to $/ 1 /$-final verb roots results in examples such as in 33.

$$
\begin{aligned}
& \text { gal- } \\
& \text { 'return home' } \\
& \begin{array}{l}
\text { bul- } \\
\text { 'spend the night' }
\end{array}
\end{aligned}
$$

In our framework, galč- behaves like č'abs- 'break (TRANs)' and is taken to be a transitivized verb stem, with $-s$ added in the lexicon. By contrast, bulč-, which behaves like gogs- 'dry something', is a causativized form to which $-s$ has been added syntactically. Since the $s$-reduction rule 31 only applies to the juxtaposition of surface /s/'s, it does not apply in these cases, and thus the prediction made in 30 can be tested (i.e., one can tell whether one or two $-s$ morphemes have been added). Consistent with our expectations, we find that the verb form galč- does indeed behave like a simple transitive verb stem in that it causativizes by the affixation of -siis.

$$
\begin{aligned}
& \begin{array}{l}
\text { galč- } \\
\text { 'bring home' }
\end{array} \\
& \begin{array}{l}
\text { (TRANS verb stem) } \\
\text { galč- }
\end{array} \\
& \begin{array}{l}
\text { CAU } \\
\text { CAU }
\end{array} \rightarrow \text { galčisiis- } \\
& \text { 'make bring home' }
\end{aligned}
$$

The verb form bulč-, on the other hand, causativizes by the addition of a single - $s$ morpheme, confirming its status as a syntactically produced causative.

(35) bulč-

$$
+-s \rightarrow \text { bulčiis }-
$$

'make spend the night' CAU 'make someone make someone (causativized INTR) spend the night'

These observations are corroborated by the fact that bulčiis- can also be interpreted as the intensive of $b u l \check{c}^{-}$, depending upon the number of appropriate arguments present. 
(36) a. terfaa-n toltuu bul-č-iis-e.

NOM spend.the.night-CAU-INT-AGR

'Terfa made[ + INT] Toltu spend the night.'

b. terfaa-n toltuu gurbaa bul-č-iis-e.

NOM boy spend.the.night-CAU-CAU-AGR

'Terfa made Toltu make the boy spend the night.'

The addition of $-s i(i) s$ to galč-, however, cannot be an intensive, since the intensive $-s$ reduplication requires the presence of a syntactically affixed $s$ causative morpheme to operate on.

(37) a. *terfaa-n toltuu galči-siis-e.

NOM bring.home-INT-AGR

'Terfa brought[ + INT] Toltu home.'

b. terfaa-n toltuu gurbaa galči-siis-e. NOM boy bring.home-CAU-AGR

'Terfa made Toltu bring the boy home.'

4. We have examined the causative construction in Oromo and have found that the observed morphological patterns can be accounted for by reference to (a) initial grammatical relations and (b) lexical vs. syntactic affixation.

In the first case, we identified the causative predicate as a bound morpheme $-s$ and showed that the number of $-s$ affixes in a causative construction corresponds to the number of its initial (logical) subjects. Thus, causatives formed with transitive or unergative stems exhibit two $-s$ morphemes, and those formed with unaccusative stems contain only one.

Further, on the basis of two types of causative-intensification patterns (affixal and periphrastic), we determined that the causative morpheme $-s$ combines DERIVATIONALLY with a subset of the unaccusative stems to form transitive verbs.

Unlike Japanese, which has both lexical and syntactic causatives formed with the same stem (cf. Shibatani 1976, McCawley 1978), the Oromo predicates that combine derivationally with $-s$ do not do so syntactically. The Japanese verb kaeru 'go home (INTR)' can form the lexical causative kaesu 'send home (TRANS)' or the syntactic causative kaeraseru 'make go home'.

(38) a. Mieko wa moo kaetta. TOP already went.home

'Mieko already went home.'

b. Taroo wa Mieko o hayaku kaesita. TOP ACC early sent.home

'Taro sent Mieko home early.'

c. Taroo wa Mieko o hayaku kaer-ase-ta. TOP ACC early go.home-CAU-PERF

'Taro made Mieko go home early.'

By contrast, the intransitive Oromo verb gal- 'return home' can only combine with $-s$ derivationally to form the transitive verb stem galč- 'bring home'.

In Japanese, there are several patterns of transitivizing morphology such that lexical causatives can be seen not to contain the syntactic causative predicate 
-(s)ase (cf. Jacobsen 1982:197-206). The examples in 39 illustrate some of the morphological patterns exhibited in Japanese transitive/inchoative pairs.

\begin{tabular}{ll}
\multicolumn{2}{c}{ Intransitive } \\
yakeru & 'burn' \\
aku & 'open' \\
agaru & 'rise' \\
kieru & 'go out' \\
odoroku & 'be surprised'
\end{tabular}

$\begin{array}{lc} & \text { Transitive } \\ \text { yaku } & \text { 'burn' } \\ \text { akeru } & \text { 'open' } \\ \text { ageru } & \text { 'raise' } \\ \text { kesu } & \text { 'extinguish' } \\ \text { odorokasu } & \text { 'surprise' }\end{array}$

In Oromo, on the other hand, the transitivizing affix and the causative affix are the same. The lexical affixation of $-s$ was shown to produce a change in the argument structure of the resultant verb stem. Such an effect is in accordance with the Projection Principle (Chomsky 1981:29), which states that argument structure changes can only occur in the process of word formation. Further, these argument structure changes are exactly what would be expected when one combines the causative $-s$ lexically with a verb stem according to Lieber's 1981 Feature Percolation Conventions.

This lexical/syntactic distinction was supported by the behavior of the causative-intensifier. We characterized the intensifier as a reduplication of the causative morpheme. Remembering that some verb forms inflected with a single $-s$ morpheme could be intensified, while others could not (cf. 13 and 14), we attributed this difference to the effect of adding $-s$ lexically in the first case and syntactically in the second. The reason that č'abs- '(make) break' cannot be intensified is that $-s$ has been added to $c$ ' $a b$ - derivationally to form a new verb stem. There is no independent causative morpheme in this construction for a reduplicative rule to act on. Thus, the form č' absiis- cannot mean '(make) break [+INT]'. On the other hand, since gogs- 'make dry' is a syntactically produced causative, the reduplicative rule CAN operate on $-s$ alone to produce gogsiis- 'make dry [+ INT]'.

A final point should be made with respect to the processes described. We have noted that the causative morpheme $-s$ can combine lexically with a limited class of predicates; that $-s$ can combine syntactically with the output of this derivation; and that the syntactically affixed causative morpheme can then undergo reduplication to form a causative-intensive. It is generally recognized that reduplicative morphology operates in the lexicon (Lieber 1981, Moravcsik 1978). If this is the case, then the reduplicative rule of causative intensification would have to take effect in the lexicon even though it is fed by the output of syntactic rules. The Oromo phenomena discussed in this paper thus provide support for the claim made by Borer 1985 that morphological rules can potentially take effect at any stage in a grammatical derivation.

\section{REFERENCES}

Borer, Hagit. 1985. Syntactic affixation and lexical affixation: The implications for theta-role assignment. Paper presented at the LSA Annual Meeting, Seattle.

Сномsку, NoAm. 1981. Lectures on government and binding. Dordrecht: Foris.

- 1982. Some concepts and consequences of the theory of government and binding. Cambridge, MA: MIT Press. 
Davies, William D., and Carol Rosen. 1988. Unions as multi-predicate clauses. Lg. 64.52-88.

Doke, C.M. 1954. The southern Bantu languages. London: Oxford University Press.

Dubinsky, STANley. 1985. Union constructions in Japanese: A unified analysis of -sase and -rare. Cornell University dissertation.

- 1988. Complex predicates in Japanese: Causative and affective union. (Studies in natural language and linguistic theory.) Dordrecht: Reidel, to appear.

GragG, Gene B. 1970. Overt and covert categories in derivational morphology. CLS 6.262-69.

- 1976. Oromo of Wellega. The non-Semitic languages of Ethiopia, ed. by Lionel Bender, 166-96. East Lansing: African Studies Center, Michigan State University.

- 1982. Oromo dictionary. East Lansing: African Studies Center, Michigan State University.

HAMP, ERIC P. 1985. Transitive and causative in Indo-European. Papers from the Parasession on Causatives and Agentivity (CLS 21:2), 64-66.

HaYward, R.J. 1976. A question in Oromo morphophonology. Folia Orientalia 17.2940.

JACOBSEN, WeSLEY. 1982. Transitivity in the Japanese verbal system. (University of Minnesota dissertation.) Bloomington: Indiana University Linguistics Club.

Jamison, Stephanie. 1976. Functional ambiguity and syntactic change: The Sanskrit accusative. Papers from the Parasession on Diachronic Syntax (CLS 12:2), 12635.

Johnson, David, and Paul Postal. 1980. Arc pair grammar. Princeton: Princeton University Press.

Lieber, Rochelle. 1981. On the organization of the lexicon. (MIT dissertation.) Bloomington: Indiana University Linguistics Club.

LloReT, Maria-Rosa. 1987. The morphophonology of the causative in Oromo. Journal of African Languages \& Linguistics 9.141-56.

Marantz, Alec. 1984. On the nature of grammatical relations. Cambridge, MA: MIT Press.

McCawley, James D. 1978. Conversational implicature and the lexicon. Syntax and Semantics 9: Pragmatics, ed. by Peter Cole, 245-59. New York: Academic Press.

Moravcsik, EDITH. 1978. Reduplicative constructions. Universals of human language. Volume 3: Word structure, ed. by Joseph Greenberg, 297-334. Stanford: Stanford University Press.

Moreno, Martino M. 1939. Grammatica teorico-practica della lingua Galla. Rome: Mondadori.

Moscati, Sabatino; Anton Spitaler; Edward Ullendorff; and Wolfram von Soden. 1964. An introduction to the comparative grammar of the Semitic languages. Wiesbaden: Harrassowitz.

Newman, Paul. 1983. The efferential (alias 'causative') in Hausa. Studies in Chadic and Afroasiatic linguistics, ed. by E. Wolff and H. Meyer-Bahlburg, 349-418. Hamburg: Buske.

Owens, Jonathan. 1985a. A grammar of Harar Oromo. (Cushitic Language Studies 4.) Hamburg: Buske.

- 1985b. The Oromo causative: lexical grammar without lexical rules. Bloomington: Indiana University Linguistics Club.

Perlmutter, David. 1980. Relational grammar. Syntax and Semantics 13: Current approaches to syntax, ed. by Edith Moravcsik and Jessica Wirth, 195-230. New York: Academic Press.

- and Paul M. Postal. 1984. The 1-advancement exclusiveness law. Studies in relational grammar 2, ed. by David Perlmutter and Carol Rosen, 81-125. Chicago: University of Chicago Press.

Plazikowsky-Brauner, Herma. 1959. Der Kausativ in den sogenannten kuschitischen Sprachen. Anthropos 54.129-40. 
Rosen, CARol. 1984. The interface between semantic roles and initial grammatical relations. Studies in relational grammar 2, ed. by David Perlmutter and Carol Rosen, 38-77. Chicago: University of Chicago Press.

Shibatani, Masayoshi. 1976. The grammar of causative constructions: A conspectus. Syntax and Semantics 6: The grammar of causative constructions, ed. by M. Shibatani, 1-40. New York: Academic Press.

Viljoen, Johannes J. 1978. A handbook of Oshiwambo (Kwanyama). Pretoria: University of South Africa Press.

Ziervogel, D. 1952. A grammar of Swazi. Johannesburg: Witwatersrand University Press.

Stanley Dubinsky

Board of Studies in Linguistics,

[Received 15 June 1987;

Cowell College revision received 8 March 1988;

University of California

Santa Cruz, CA 95064

Maria-Rosa Lloret \& Paul Newman

Department of Linguistics

Indiana University

Bloomington, IN 47405 